\title{
Gelation by Linking of Growing Spherulites in Poly(4-methyl-1-pentene)/ Cyclohexane Solution
}

\author{
Tetsuya Tanigami, Kazuteru En, Kazuo Yamaura, \\ and Shuji MATSUZAWA \\ Department of Chemistry, Faculty of Textile Science and Technology, \\ Shinshu University, Ueda, Nagano 386, Japan
}

(Received June 21, 1985)

\begin{abstract}
One of the two types of gelation in a cyclohexane solution of poly(4-methyl-1pentene) is caused by linking of growing spherulites which are nucleated from the one-phase solution. The mechanism is related to that of the spherulitic crystallization by using the Avrami equation. The rate of the crystallization can be estimated by a simple method which takes advantage of the variety of crystal morphology.

KEY WORDS Thermo-reversible Gelation / Spherulite / Crystalline Particle / Morphology / Crystallization / Avrami Equation / Poly(4-methyl1-pentene) /
\end{abstract}

Recently, thermo-reversible gelation of polymers from solution was investigated in relation to liquid-liquid phase separation. Chosen for this were poorly crystallizable and amorphous polymers such as polyacrylonitrile, ${ }^{1}$ poly(vinyl alcohol), ${ }^{1-3}$ atactic polystyrene, ${ }^{4}$ isotactic polystyrene, ${ }^{5}$ agar, ${ }^{6}$ and gelatin. ${ }^{1.2}$ Unfortunately, solutions of highly crystalline polymers such as polyolefines have not been studied from this viewpoint, owing to the very fast rate of crystallization and their complicated structures. We could, however, explain the relation between liquid-liquid phase separation and crystallization in a highly crystalline polymer of poly(4-methyl-1-pentene) (P4M1P)/cyclohexane gel, using peculiar morphology and variety of polymorphism of this polymer. ${ }^{7}$

In the gel of P4M1P, two types of gelation mechanisms were found: one gelation is caused by the liquid-liquid phase separation which precedes the crystallization, and another gelation is caused by linking of the growing spherulites or crystalline particles from the one-phase solution. The mechanism of the nucleation and growth observed for the latter crystalline species was considered to be almost identical with that for general solutioncrystallization. There is a critical polymer concentration that distinguishes the gelation from the general solution-crystallization. If the concentration is higher than the critical value, the three-dimensional linking of the crystalline species stops the flow of its system. This is the gelation from one-phase solution of highly crystalline polymers.

In this paper, the gelation mechanism by the spherulitic crystallization from the one-phase solution, which was visually observed in the previous work, ${ }^{7}$ was more precisely analyzed by using the Avrami equation. ${ }^{8}$ 


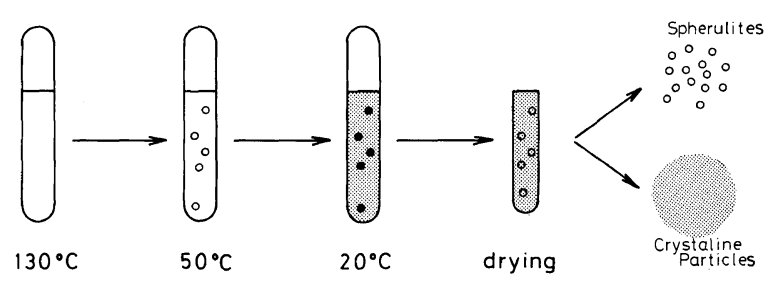

Figure 1. The method for estimation of the weight fraction of spherulites.

\section{EXPERIMENTAL}

\section{Solution Preparation}

A commercial isotactic P4M1P sample (TPX ${ }^{\circledR}$, MX019, Mitsui Petrochemical Co., Ltd., Japan) was used throughout this work. The solution was prepared by dissolving the polymer at $130^{\circ} \mathrm{C}$ in $2.5 \mathrm{ml}$ of cyclohexane at a desired polymer concentration $c$ (in $\mathrm{g} \mathrm{ml}^{-1}$ ) in a sealed test-tube with $12 \mathrm{~mm}$ diameter and $110 \mathrm{~mm}$ length.

\section{Estimation of Fraction of Spherulite}

The weight fraction of the polymer converted to the spherulites $\left(X_{\mathrm{s}}\right)$ was measured as a function of crystallization time by using a simple method as shown in Figure 1. The method takes advantage of the variety of morphology observed in this system. ${ }^{7}$ The procedure was as follows: [1] The solution was quenched from $130^{\circ} \mathrm{C}$ to $50^{\circ} \mathrm{C}$. After a while, the transparent spherulites could be detected by the naked eye, since they were extraordinarily big $(0.5-2 \mathrm{~mm}$ diameter $)$ and had a slightly different refractive index from that of the solution. Furthermore; it was easy to observe the spherulite growth owing to the slow rates of the growth and nucleation. [2] The sample was maintained at $50^{\circ} \mathrm{C}$ for a period of $t$ and subsequently quenched to $20^{\circ} \mathrm{C}$. The solution part that was not converted into spherulites at $50^{\circ} \mathrm{C}$ was immediately occupied by small white crystalline particles. At the same time the non-crystallized part remained within the spherulites at $50^{\circ} \mathrm{C}$ was further crystallized associating with whitening. However, this secondary crystallization within the spherulites never changes the size of the spherulites. Thus, the fraction of the spherulites in time $t$ could be held semipermanently by the quenching. [3] After the $24 \mathrm{~h}$-storing at $20^{\circ} \mathrm{C}$, the gel was dried in vacuo. Finally, the spherulites and the crystalline particles were separated by hand. As the former were big, transparent, and hard while the latter were small, white, brittle, and powdery, the separation was very easy. $X_{\mathrm{s}}$ was calculated from the weight fraction of the spherulites in the dried gel.

Thus derived $X_{\mathrm{s}}$ as a function of time shows only the rate of spherulite growth at the extra interface of the spherulites touched with the solution, since the secondary crystallization within the spherulites is forcibly completed by quenching. The form $\mathrm{V}$ crystals were only observed in the spherulites, while the form II were observed in the crystalline particles. $^{7}$ There was no case of mixtures of the two forms.

\section{RESULTS AND DISCUSSION}

Isothermal growth rates of the spherulite in the two different concentrations are shown in Figure 2. The isotherms show characteristic sigmoidal shapes. The crystallization kinetics are usually interpreted in terms of the Avrami equation: ${ }^{8}$

$$
X_{\mathrm{s}}=1-\exp \left(-k t^{n}\right)
$$

where $k$ is a rate constant that depends on nucleation and growth rates, $t$ the time, and $n$, a number that depends on the geometry of the crystal growth and the nucleation type. The 


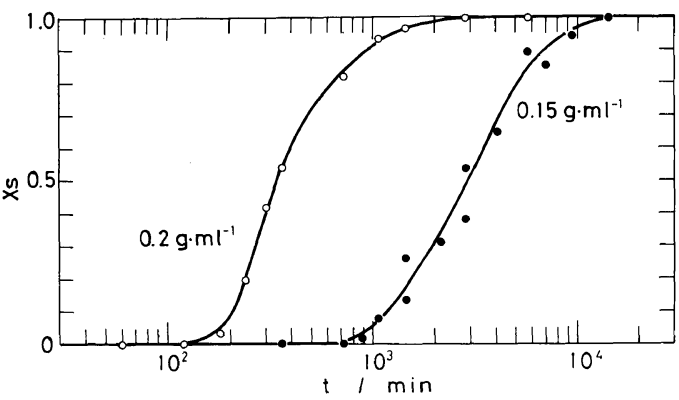

Figure 2. Variation of weight fraction of spherulites during isothermal gelation at $50^{\circ} \mathrm{C}$.

isotherms in Figure 2 were re-plotted as shown in Figure 3 (the Avrami plot). For both concentrations, the growth process divided into two parts by two straight lines. The coordinates of the intersection of the two lines are denoted as $\left(t_{\mathrm{g}}, X_{\mathrm{sg}}\right)$. The coordinates are listed in Table I, along with the Avrami exponents derived from the slopes of the lines.

The induction time for the gelation at $50^{\circ} \mathrm{C}$ as shown by circles in Figure 4 had already been measured by the "test tube inverting" method. ${ }^{7}$ Three characteristic times for the appearance of the spherulite $\left(t_{\mathrm{i}}\right)$, for the termination of the growth $\left(t_{\mathrm{f}}\right)\left(X_{\mathrm{s}}=1.0\right)$, and for $X_{\mathrm{s}}=X_{\mathrm{sg}}\left(t_{\mathrm{g}}\right)$ are also plotted in this figure. Although small spherulites about $0.1 \mathrm{~mm}$ in diameter could be observed in the solution in the initial stage of the crystallization, it was very difficult to take them out from the dried gel. Therefore, the $t_{\mathrm{i}}$ would be overestimated by this method. It should be noticed that the gelation occurred during the growth process of the spherulite $\left(t_{\mathrm{i}}<t<t_{\mathrm{f}}\right)$, and $t_{\mathrm{g}}$ agreed very well with the gelation time.

As reported in the previous paper, ${ }^{7}$ the gelation was accomplished by the linking of the growing spherulites. This is supported by the change of the Avrami exponent through the gelation. The values of $3<n<4$ before the gelation indicate the three-dimensionally free growth of the spherulite. The small values $1<n<2$ after the gelation can be attributed to the secondary growth toward the gap formed

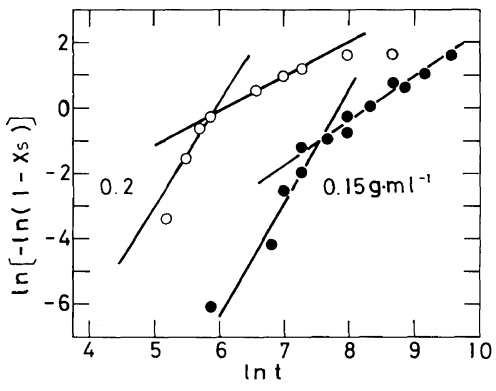

Figure 3. The Avrami plot for the data in Figure 2.

Table I. Characteristic parameters from the Avrami plots in Figure 3

\begin{tabular}{lrrrr}
\hline & & & \multicolumn{3}{c}{$n$} \\
\cline { 4 - 5 }$c / \mathrm{g} \mathrm{ml}^{-1}$ & $t_{\mathrm{g}} / \mathrm{min}$ & $X_{\mathrm{sg}}$ & $t<t_{\mathrm{g}}$ & $t_{\mathrm{g}}<t$ \\
& & & 3.2 & 1.1 \\
& & & & \\
\hline 0.15 & 1840 & 0.28 & 3.5 & 1.4 \\
\hline
\end{tabular}

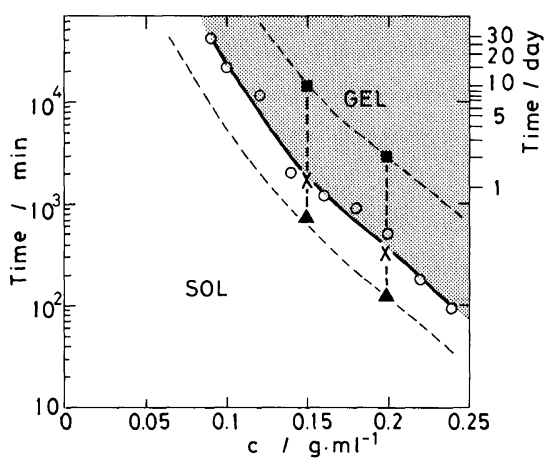

Figure 4. Relation between spherulitic growth and gelation at $50^{\circ} \mathrm{C}$. Four characteristic times are plotted: $\bigcirc$, for gelation determined by the "test-tube inverting" method; $\boldsymbol{\Delta}$, for the appearance of the spherulite $\left(t_{\mathrm{i}}\right)$; $\boldsymbol{\square}$, for the termination of the growth $\left(t_{\mathrm{f}}\right)$ and $\times$, for $X_{\mathrm{s}}=X_{\mathrm{sg}}\left(t_{\mathrm{g}}\right)$.

by the linking. However, the yielded $n$ values in the pre-gelation stage are less than the value of 4 expected for sporadic nucleation and three-dimensional free growth. This deviation may be caused by complicated effects as follows. The first effect is the experimental error in the estimation of $X_{\mathrm{s}}$ in the early stage of the crystallization. The second is the localized 


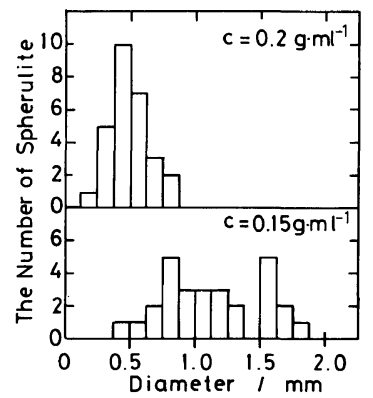

Figure 5. Distribution of spherulite diameter measured in the dried state.

nucleation due to a very small amount of dust. The third is very slow settlement of the growing spherulites toward the bottom. The settling rate was at most $-1 \mathrm{~mm} /$ day. Although the main motive force for the linking is the spherulite growth, the settlement slightly accelerates the local linking rate in the vicinity of the bottom. The fourth is the effect of the interface area of the solution with air and the tube where the growth is largely restrained. In the case of extraordinarily big spherulites such as in our case, the fraction of the spherulite grown at the interface cannot be neglected. A larger volume of the solution should be used for this work.

Figure 5 shows the distribution of the spherulite size at the onset time of the gelation. Its concentration dependency is clear; the smaller spherulites $\left(c=0.2 \mathrm{~g} \mathrm{ml}^{-1}\right)$ have the narrower distribution owing to the larger frequency of the nucleation in the more concentrated solution. The size difference also contributed to the dependency of the value of $X_{\text {sg }}$ on the concentration, as shown in Table I.

As stated above, the gelation mechanism of this case can be analyzed by the Avrami equation. The nucleated spherulites grow freely and three-dimensionally until they impinge upon one another to make a linked structure in which the solvent is occluded. In spite of the simple structure, such a mechanism had not been reported in crystalline polymers until the extraordinarily big spherulites were found by us. Probably the term "gel" might have been used familiarly for non-crystalline gel and/or gel formed by the liquid-liquid phase separation (gel in a narrow sence). Thus, the spherulitic gelation may be considered to be a special case of crystallization or the gelation in a broad sence. Here, however, we stress that the individual spherulite itself can be regarded as a micro gel in contrast with spherulites crystallized from melt, because it contains solvent.

\section{REFERENCES}

1. A. Labudzinska and A. Ziabicki, Kolloid Z. Z. Polym., 243, 21 (1971).

2. E. Pines and W. Prins, Macromolecules, 6, 888 (1973).

3. M. Komatsu, T. Inoue, and K. Miyasaka, Sen-i Gakkaishi, 40, 316 (1984).

4. S. Wellinghoff, J. Shaw, and E. Baer, Macromolecules, 12, 932 (1979); H. M. Tan, A. Moet, A. Hiltner, and E. Baer, Macromolecules, 16, 28 (1983); M. Tan, B. H. Chang, E. Baer, and A. Hiltner, Eur. Polym. J., 19, 1021 (1983); R. F. Boyer, E. Baer, and A. Hiltner, Macromolecules, 18, 427 (1985).

5. J. M. Guenet, B. Lotz, and J. C. Wittmann, Macromolecules, 18, 420 (1985).

6. G. T. Feke and W. Prins, Macromolecules, 7, 527 (1974).

7. T. Tanigami, H. Suzuki, K. Yamaura, and S. Matsuzawa, Macromolecules, in press.

8. C. Dovoy, L. Mandelkern, and 1. Bourland, $J$. Polym. Sci., A-2, 8, 869 (1970). 